\title{
Study of Wear Rate On Graphene and S-Glass Reinforced Al- 6061 Metal Matrix Composites
}

\author{
Verma R. ${ }^{* 1}$, Dr. P. Vijaya Kumar ${ }^{2}$, Meghashree K. A. ${ }^{3}$, Puneeth P. ${ }^{3}$ \\ ${ }^{*}$ Research Scholar, Dechanical Engineering Department, UVCE, Bangalore, Karnataka, India \\ ${ }^{2}$ Professor,Mechanical Engineering Department, UVCE, Bangalore, Karnataka, India \\ ${ }^{3} \mathrm{PG}$ Scholar, Mechanical Engineering Department, UVCE, Bangalore, Karnataka, India
}

\begin{abstract}
This research work investigated the effect of the graphene and S-glass fiber on the wear rate of the Al6061 / SGlass \& Graphene particulate MMCs. Metal Matrix Composites (MMC's) consist of either pure metal or an alloy as the matrix material, while the reinforcement generally a ceramic material. Aluminium composites are considered as one of the advanced engineering materials which have attracted more and more benefits. Now a days these materials are widely used in space shuttle, commercial airlines, electronic substrates, bicycles, automobiles, etc., Among the MMC's aluminium composites are predominant in use due to their low weight and high strength. The key features of MMC's are specific strength and stiffness, excellent wear resistance, high electrical and thermal conductivity. Hence, it is proposed to form a new class of composite. The Al 6061(Aluminium alloy 6061) reinforced with graphene and S-glass fiber to form MMCs were investigated. The stir casting technique of liquid metallurgy was used for the fabrication of the composite material. The composite was produced for different percentages of graphene and S-Glass fiber(varying Graphene with constant S-Glass fiber and varying S-Glass fiber with constant Graphene percentage). The specimens were prepared as per ASTM standard size by turning and facing operations to conduct corrosion tests and they were tested using pin on disk apparatus with varying load and speed in different comobinations. Through the results, it is concluded that wear rate increased with the increase in speed and load for every combination of the composite. However with Graphene being the main reinforcement with addition of Graphene wear rate has reduced marginally.
\end{abstract}

Keywords : Al 6061, Graphene, S-Glass fiber, Wear rate, Pin on Disk Apparatus.

\section{INTRODUCTION}

In this research paper we study the variation of wear rate of different compositions of the hybrid composites, material preparation for the test, test the specimen, results and conclusion. Aluminium is the most popular matrix for the metal matrix composites (MMCs). The $\mathrm{Al}$ alloys are quite attractive due to their low density, their capability to be strengthened by precipitation, their good corrosion resistance, high thermal and electrical conductivity, and their high damping capacity. They offer a large variety of mechanical properties depending on the chemical composition of the $\mathrm{Al}$ - matrix. They are usually reinforced by $\mathrm{Al}_{2} \mathrm{O}_{3}, \mathrm{SiC}, \mathrm{C}$ but $\mathrm{SiO}_{2}, \mathrm{~B}, \mathrm{BN}, \mathrm{B} 4 \mathrm{C}, \mathrm{AlN}$ may also be considered.

In the 1980s, transportation industries began to develop discontinuously reinforced AMCs. They are very attractive for their isotropic mechanical 
properties and their low costs. MMCs are nearly always more expensive than the more conventional materials they are replacing. As a result, they are found where improved properties and performance can justify the added cost. Today these applications are found most often in aircraft components, space systems and high - end or "boutique" sports equipment. The scope of applications will certainly increase as manufacturing costs are reduced.

Wear is the progressive loss of material from the operating surface of a solid occurring as a result of motion between two surfaces. Wear appears as if it occurs due to relativemotion between two bodies which are solid. There can be different modes of forms of wear such as abrasion, adhesion (scuffing, wiping, welding, galling and scoring), erosion and fatigue. When two surfaces which appear smooth macroscopically are brought together then contact occurs at isolated asperities on the surfaces. According to the profilometry studies most of the solid surfaces inherently have roughness with varying degrees. It is often found that wear volume or wear rate is inversely proportional to hardness of the materials which are in contact given that hardness is proportional to the yield strength of the same materials.

The main objective of this project is to develop $\mathrm{Al}$ (6061)/ S-Glass \& Graphene particulate MMCs where the S-glass \& Graphene are used as reinforcement material \& $\mathrm{Al}$ (6061) is used as matrix material. The different weight $\%$ of reinforcement will be added to matrix and liquid casting technique for the preparation of Al (6061)/ S-Glass \& Graphene MMCs thus the developed composites will be tested for corrosion behavior.

A. K. Dhingra (1986) [1], had derived that the composite structures have shown universally a savings of at least $20 \%$ over metal counterparts and a lower operational and maintenance cost. R.L. Trumper (1987) [2], stated that the researchers all over the world are focusing mainly on Aluminium because of its unique combination of good corrosion resistance, low density and excellent mechanical properties. The unique thermal properties of Aluminium composites such as metallic conductivity with coefficient of expansion that can be tailored down to zero, add to their prospects in aerospace and avionics. MechmetAcilar, FerhatGul (2004) [3], have shown in their work that the choice of Silicon Carbide as the reinforcement in Aluminium composite is primarily meant to use the composite in missile guidance system replacing certain beryllium components because structural performance is better without special handling in fabrication demanded by latter"s toxicity. A.Alahelisten (1996) [4], J.Q.Jiang (1996) [5] P.N.Bindhumadhan (2001) [6], stated that though their low density (35\% lower than that of $\mathrm{Al}$ ) makes them competitive in terms of strength/density values. Magnesium alloys do not compare favorably with Aluminium alloys in terms of absolute strength. The reason for Aluminium being a success over magnesium is said to be mainly due to the design flexibility, good wettability and strong bonding at the interface.

In this present investgation, the effect of S-Glass \& Graphene particle with Aluminium \& its percentage will be studied. Thus this will aid in reaching an optimum weight of percentage reinforcement the specific objective \& scope of the present investigation.

\section{METHODS AND SPECIMEN PREPARATION}

\section{APPARATUS}

Figure 1 shows a typical pin - on - disk wear test system. This consists of a motor drive, revolution counter, specimen holder and a lever-arm device to 
hold the pin. Rotating speeds of motor drive are typically in the range 0.3 to $3 \mathrm{rad} / \mathrm{s}$ ( 60 to $600 \mathrm{r} / \mathrm{min}$ ).

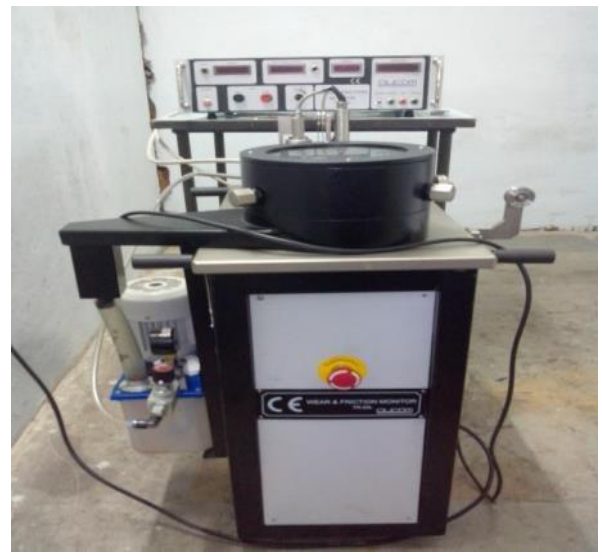

Fig. 1 Pin on Disk Apparatus

\section{TEST SPECIMENS}

Materials: This test method may be applied to a variety of materials. The only requirement is that specimens dimensions can be prepared and that they will withstand the stresses imposed during the test without failure or excessive flexure. The materials being tested shall be described by dimensions, surface finish, material type, form, composition, microstructure, processing treatments, and indentation hardness.

Test Specimens: The typical pin specimen is cylindrical or spherical in shape. Typical cylindrical or spherical in shape. Typical cylindrical or spherical pin specimen diameters range from 2 to $10 \mathrm{~mm}$. The typical disk specimen diameters range from 30 to $100 \mathrm{~mm}$ and have a thickness in the range of 2 to $10 \mathrm{~mm}$.

Surface Finish: A ground surface roughness of $0.8 \mu \mathrm{m}$

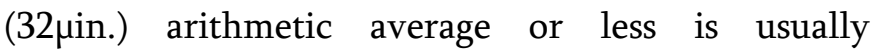
recommended.

\section{CASTING}

\section{Fabrication of Test Specimens}

Stir casting technique of liquid metallurgy is used to prepare Al 6061 Hybrid composites.It consist of resistance Muffle-furnace and a stirrer assembly was used to synthesize the composite.

\section{Preheating of reinforcement}

Muffle furnace was used to preheat the particulate to a temperature of $700^{\circ} \mathrm{C}$. It was maintained at the temperature till it was introduced in to the $\mathrm{Al} 6061$ alloy melt.

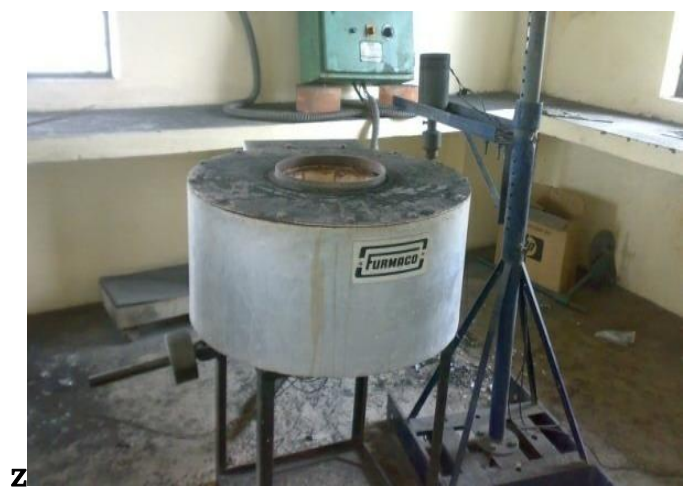

Fig. 1 Furnace setup

\section{Melting of matrix alloy}

The melting range of $\mathrm{Al} 6061$ alloy is of $700-800^{\circ} \mathrm{C}$. A known quantity of $\mathrm{Al} 6061$ ingot wear pickled in 10\% $\mathrm{NaOH}$ solution at room temperature for $10 \mathrm{~min}$. The smut formed was removed by immersing the ingots for 1 min mixture of one part nitric acid and one part water followed washing in methanol. The cleaned ingot after drying in air were loaded into the graphite crucible of the furnace for melting. The melt was super-heated to a temperature of $800^{\circ} \mathrm{C}$ and maintained at that temperature. The molten metal was then degassed using Hexa-Chloro ethane tablets for about $8 \mathrm{~min}$. 


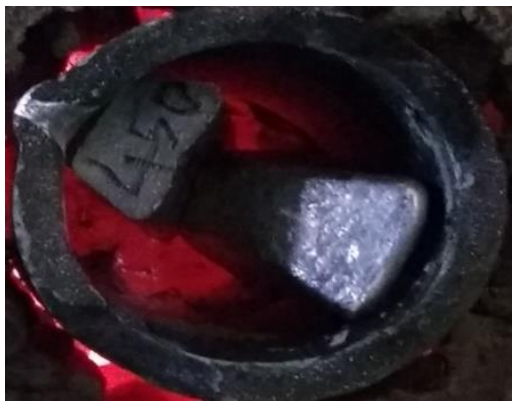

Fig. 2 Melting Ingots

\section{Mixing and stirring}

Alumina coated stainless steel impeller was used to stir the molten metal to create a vertex. The impeller was of centrifugal type with three blades welded at $45^{\circ}$ inclination and $120^{\circ}$ apart. The stirrer was rotated at a speed 300-400 rpm and a vertex was created in the melt. The depth of immersion of impeller was approximately one third of the height of the molten metal. From the bottom of the crucible. The preheated particulates of Graphene and short S-Glass fiber were introduced into the vertex at the rate of $120 \mathrm{gm} / \mathrm{min}$. Stirring was continued until interface interactions between the particles and the matrix promoted wetting. The melt was degassed using Hexo chloro ethane tablets and after reheating to superheated temperature $\left(800^{\circ} \mathrm{C}\right)$ it was poured into the preheated die.

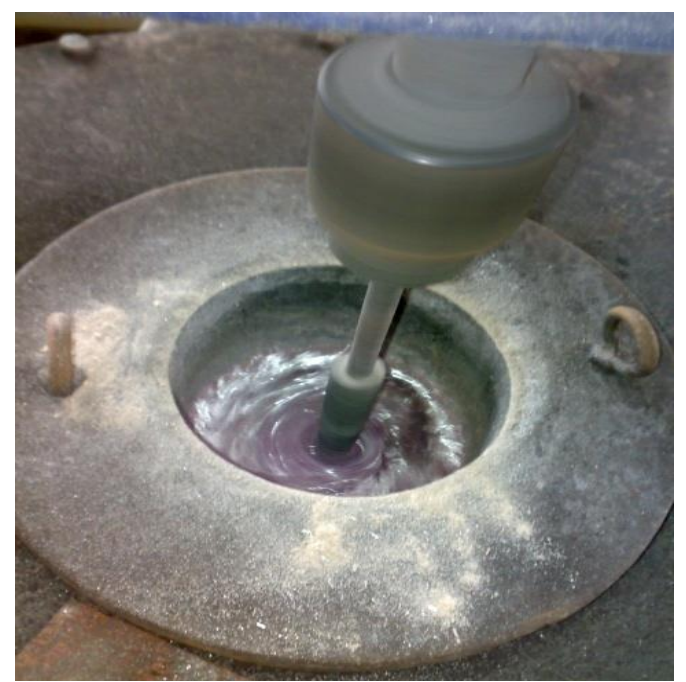

Fig. 3 Mechanical Stirrer in action

\section{Pouring of molten metal into dies}

Then after few minutes of stirring, the liquid metals with reinforcements are poured into the dies to get the required castings. The dies were are preheated and coated additives to ease the process of removing the casting.

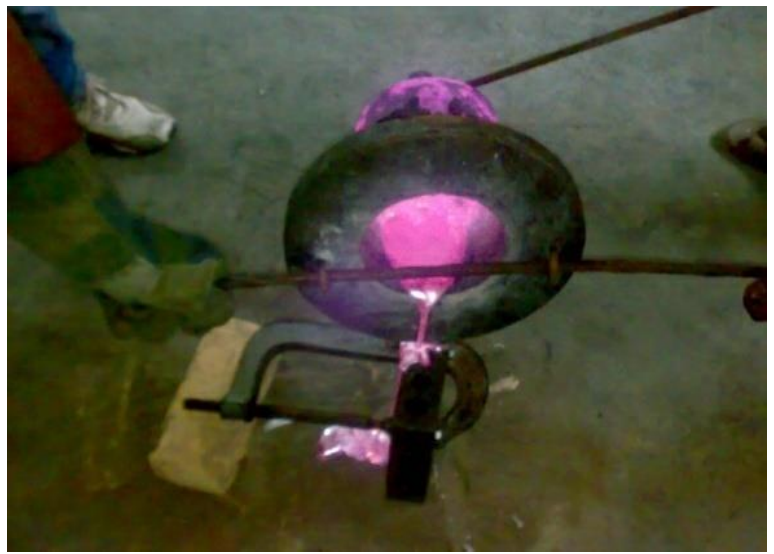

Fig. 4 Pouring of metal

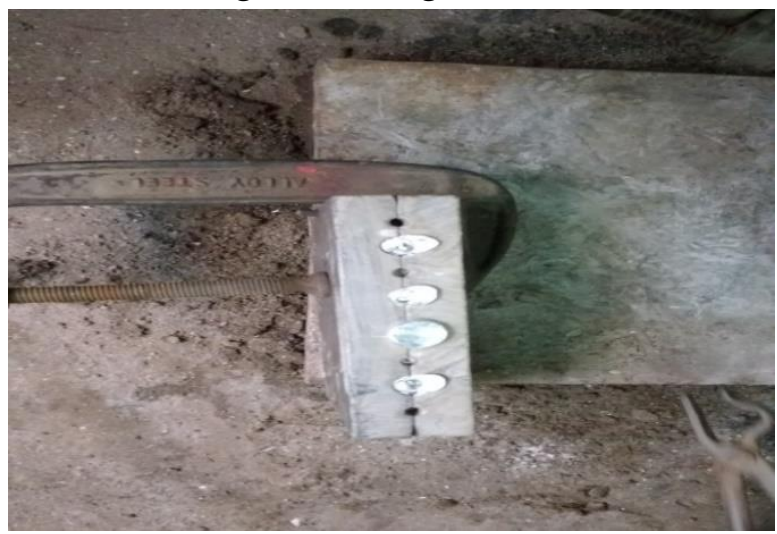

Fig. 5 Casted Specimen in the die

\section{SPECIMEN PREPARATION}

The wear test was conducted using a pin-on-disc computerized wear testing machine as shown in figure in accordance with ASTM standards G99-95. The test uses the specimens of diameter of $6 \mathrm{~mm}$ and length $25 \mathrm{~mm}$ machined from the cast specimens. 


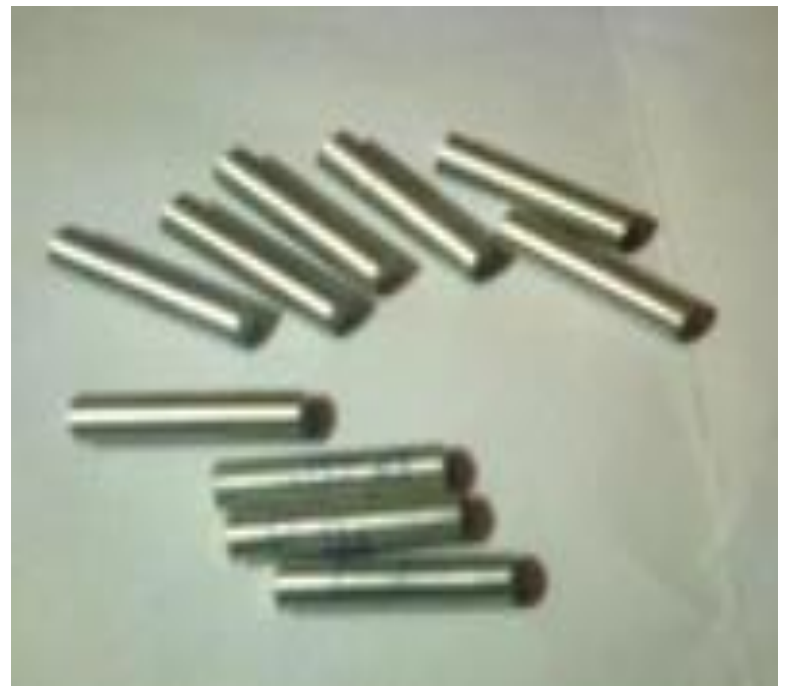

Fig. 6 Wear test specimens

The percentage of reinforcements used in different specimens is as shown in table 1

Table 1: Percentage of Reinforcements

\begin{tabular}{|c|c|c|c|}
\hline Specifications & $\begin{array}{c}\% \\
\text { Graphene }\end{array}$ & $\begin{array}{c}\% \text { S-Glass } \\
\text { Fiber }\end{array}$ & $\begin{array}{c}\% \text { of Al- } \\
6061\end{array}$ \\
\hline A0.5G1S & 0.5 & 1 & 98.5 \\
\hline A0.5G3S & 0.5 & 3 & 96.5 \\
\hline A0.5G5S & 0.5 & 5 & 94.5 \\
\hline A1G1S & 1 & 1 & 98 \\
\hline A1G3S & 1 & 3 & 96 \\
\hline A1G5S & 1 & 5 & 94 \\
\hline A1.5G1S & 1.5 & 1 & 97.5 \\
\hline A1.5G3S & 1.5 & 3 & 95.5 \\
\hline A1.5G5S & 1.5 & 5 & 93.5 \\
\hline A2G1S & 2 & 1 & 97 \\
\hline A2G3S & 2 & 3 & 95 \\
\hline A2G5S & 2 & 5 & 93 \\
$\bullet$
\end{tabular}

\section{PROCEDURE:}

- Immediately prior to testing, and prior to measuring or weighing, clean and dry the specimens. Take care to remove all dirt and foreign matter from the specimens. Use non-chlorinated, non- $(\mathrm{lm}$-forming cleaning agents and solvents. Dry materials with open grains to remove all traces of the cleaning fluids that may be entrapped in the material. Steel (Ferromagnetic) specimens having residual magnetism should be demagnetized. Report the methods used for cleaning.

- Measure appropriate specimen dimensions to the nearest $2.5 \mu \mathrm{m}$ or weigh the specimens to the nearest $0.0001 \mathrm{~g}$.

- Insert the disk securely in the holding device so that the disk is fixed perpendicular $\left(61^{\circ}\right)$ to the axis of the resolution.

- Insert the pin specimen securely in its holder and, if necessary, adjust so that the specimen is perpendicular $\left(61^{\circ}\right)$ to the disk surface when in contact, in order to maintain the necessary contact conditions.

- Add the proper mass to the system lever or bale to develop the selected force pressing the pin against the disk.

- Start the motor and adjust the speed to the desired value while holding the pin specimen out of contact with the disk. Stop the motor.

- Set the revolution counter (or equivalent) to the desired number of revolutions.

- Begin the test with the specimens in contact under load. The test is stopped when the desired number of revolutions is achieved. Tests should not be interrupted or restarted.

- Remove the specimen and clean off any loose wear debris. Note the existence of features on or near the wear scar such as: protrusions, displaced metal, discoloration, micro cracking or spotting.

- Re-measure the specimen dimensions to the nearest $2.5 \mu \mathrm{m}$ or reweigh the specimens to the nearest $0.0001 \mathrm{~g}$, as appropriate.

\section{FORMULAE}

Wear rate $=$ V/S IN $\left(\mathrm{mm}^{3} / \mathrm{m}\right)$

Where, $\mathrm{V}=$ Volume of wear $\mathrm{m} 3=\mathrm{v} 1-\mathrm{v} 2$

$\mathrm{V}_{1}=\pi \mathrm{r}^{2} \mathrm{~L}_{1}$

$\mathrm{V}_{2}=\pi \mathrm{r}^{2} \mathrm{~L}_{2}$ 
$\mathrm{r}=$ radius of specimen

$\mathrm{L}_{1}=$ Initial length of specimen $\mathrm{L}_{2}=$ final length of specimen $\mathrm{Or}$

$\mathrm{S}=$ Sliding distance $(\mathrm{m})=\pi^{*} \mathrm{D}^{*} \mathrm{~N}^{*} \mathrm{~T}=2^{*} \pi^{*} \mathrm{R}^{*} \mathrm{~N}^{*} \mathrm{~T}$

$\mathrm{D}=$ Diameter of wear track in meter

$\mathrm{R}=$ Radius of wear track in meter

$\mathrm{N}$ = Speed of the wheel in rpm

$\mathrm{T}=$ Sliding time in minutes

\section{III.RESULTS AND DISCUSSION}

\section{WEAR RATE ANALYSIS:}

Wear rate of the composite under various combinations of loads and speeds are discussed below.

\section{For 1N load:}

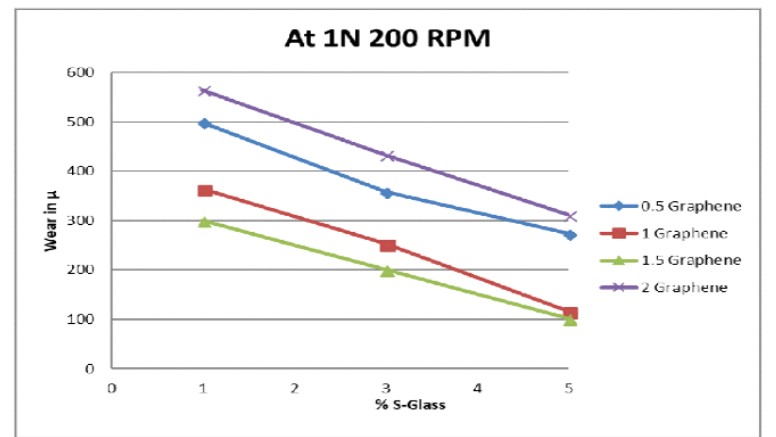

Graph-1 Specimen with 1N load at $200 \mathrm{rpm}$ speed

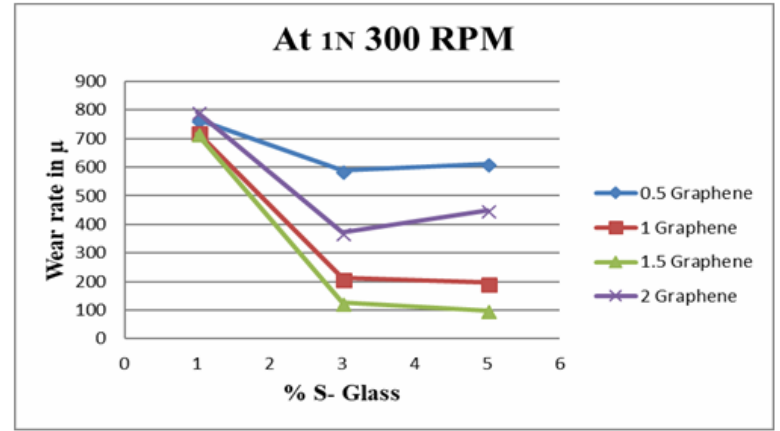

Graph-2 Specimen with $1 \mathrm{~N}$ load at $300 \mathrm{rpm}$ speed

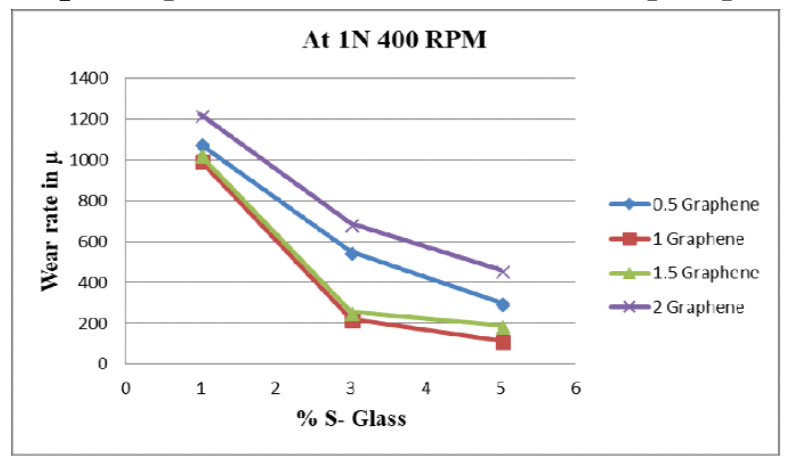

Graph-3 Specimen with 1N load at $400 \mathrm{rpm}$ speed

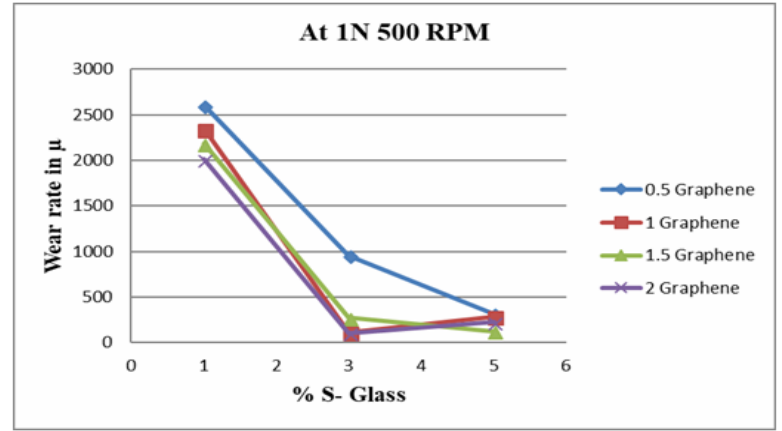

Graph-4 Specimen with 1N load at $500 \mathrm{rpm}$ speed As seen in above graphs (1-4) the wear rate decreases as the percentage of Graphene and S - Glass increases from $1 \%, 3 \%$, and $5 \%$ in $1.5 \%$ Graphene, S - Glass reinforced $\mathrm{Al} 6061$ based hybrid MMC, at $1 \mathrm{~N}$ load and different speeds, and at track diameter of $100 \mathrm{~mm}$ in pin on disc experiment, this is because of increase in the amount of reinforcements in MMC.

\section{For 2N Load:}

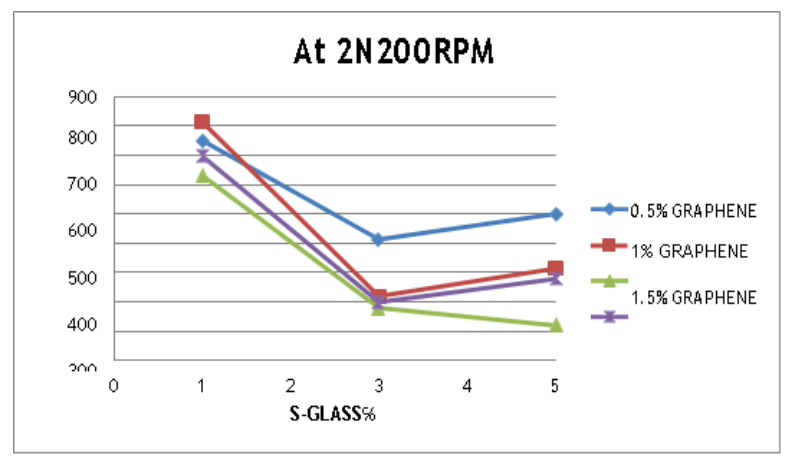

Graph-5 Specimen with 2N load at 200 rpm speed

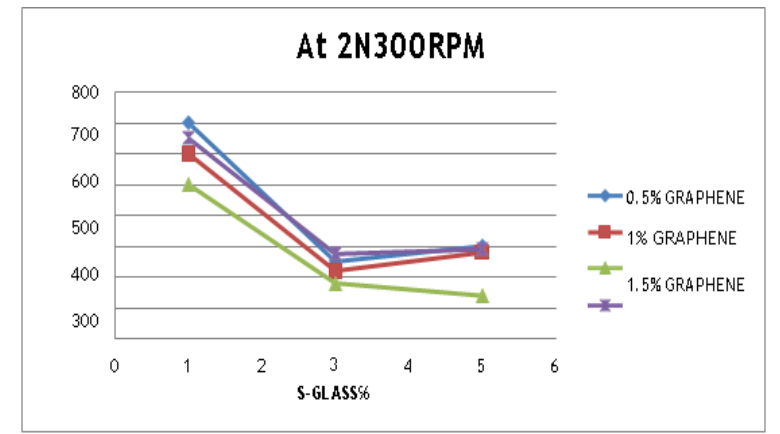

Graph-6 Specimen with 2N load at $300 \mathrm{rpm}$ speed 


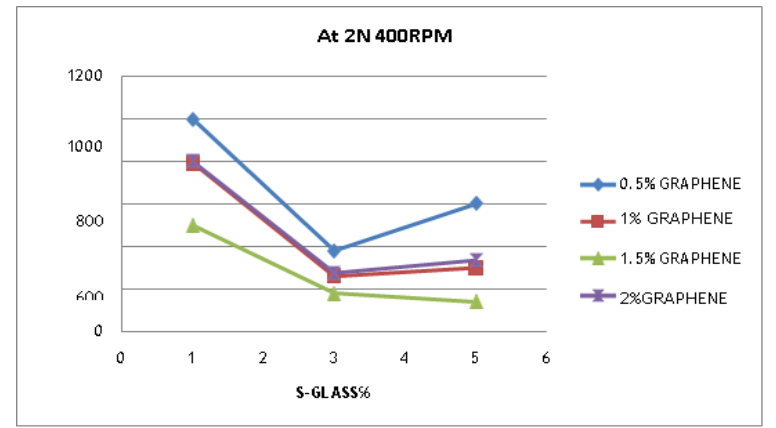

Graph-7 Specimen with 2N load at $400 \mathrm{rpm}$ speed

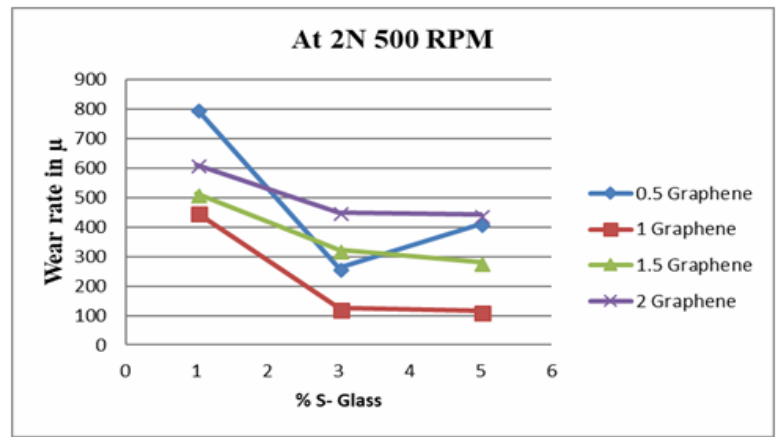

Graph-8 Specimen with 2N load at 500 rpm speed

As seen in above graphs (4-8) the wear rate decreases as the percentage of Graphene and $\mathrm{S}$ - Glass increases from $1 \%, 3 \%$, and $5 \%$ in $1.5 \%$ Graphene, $\mathrm{S}-$ Glass reinforced Al 6061 based hybrid MMC, at 2N load and different speeds, and at track diameter of $100 \mathrm{~mm}$ in pin on disc experiment, this is because of increase in the amount of reinforcements in MMC.

\section{For 3N Load:}

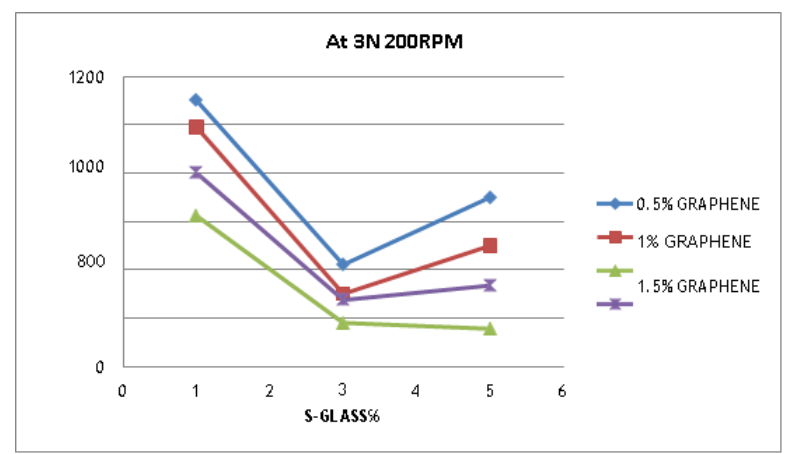

Graph-9 Specimen with 3N load at 200 rpm speed

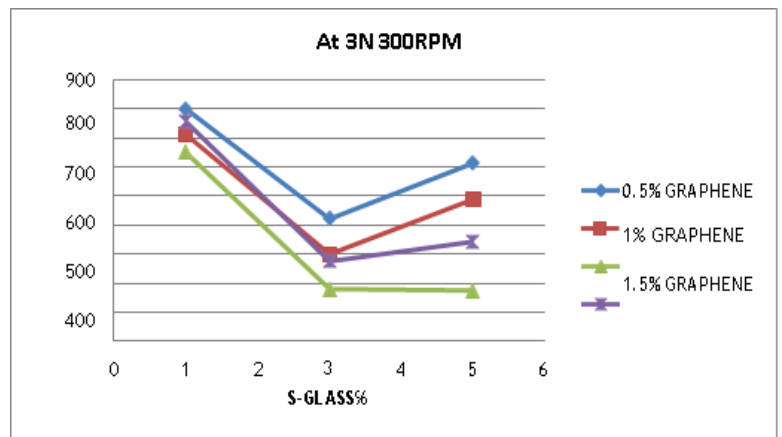

Graph-10 Specimen with 3N load at $300 \mathrm{rpm}$ speed

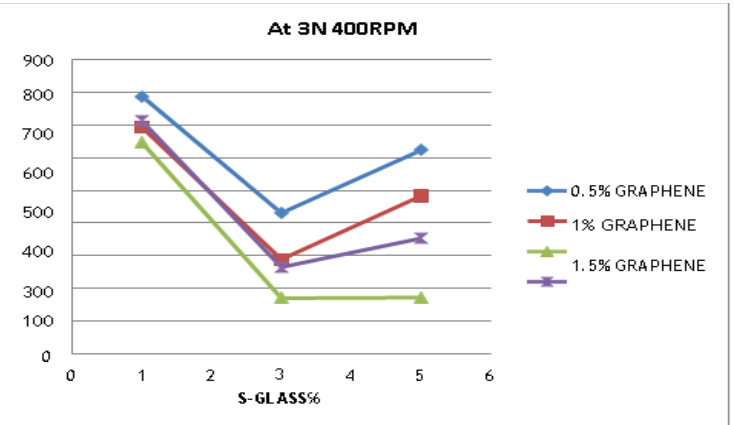

Graph-11 Specimen with 3N load at $400 \mathrm{rpm}$ speed

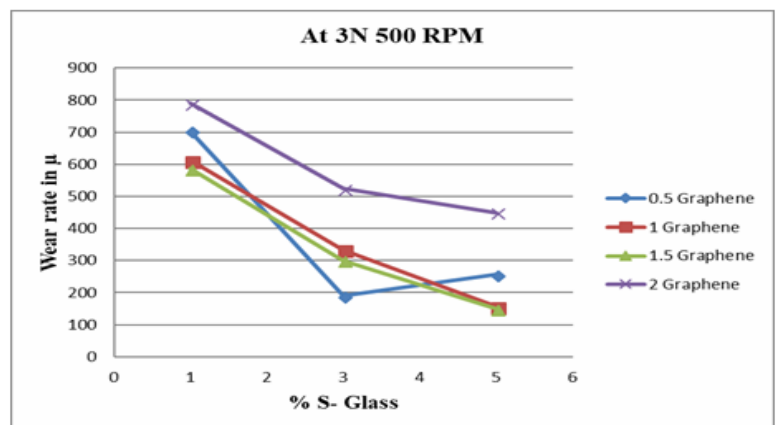

Graph-12 Specimen with 3N load at 500 rpm speed

As seen in above graphs (9-12) the wear rate decreases as the percentage of Graphene and S - Glass increases from $1 \%, 3 \%$, and $5 \%$ in $1.5 \%$ Graphene, $\mathrm{S}-$ Glass reinforced $\mathrm{Al} 6061$ based hybrid MMC, at 3N load and different speeds, and at track diameter of $100 \mathrm{~mm}$ in pin on disc experiment, this is because of increase in the amount of reinforcements in MMC.

Wear rate increased with the increase in speed and load for every combination of the composite. However with Graphene being the main reinforcement with addition of Graphene wear rate has reduced marginally. Addition of $\mathrm{S}-$ glass also to some extent decreased the wear rate but Graphene 
plays a major role in reducing the wear rate, Graphene is been semi-metal material. Above the critical load, transition to severe wear occurs in unreinforced matrix alloy. But the reinforced MMCs have superior wear resistance. With increase in Graphene wear rate has decreased and is clear from the results that as the percentage of $\mathrm{S}$ - Glass increases in the composite the wear rate decreases, which is a good sign for production of low cost material.

\section{IV.CONCLUSION}

The effect of Graphene and S-glass particles on the sliding wear resistance in Al-6061 alloys varies with the applied load and speed. From the experiments conducted to study the effect on adding various volume fraction of S-Glass and Graphene with Al6061 for the wear properties. The following conclusion can be drawn.

- Composite material of Al-6061 reinforced with SGlass fibre and Graphene was successfully casted.

- Wear rate increased with the increase in speed and load for every combination of the composite. However with Graphene being the main reinforcement with addition of Graphene wear rate has reduced marginally. Addition of $\mathrm{S}$ - glass also to some extent decreased the wear rate but Graphene plays a major role in reducing the wear rate, Graphene is been semi-metal Material.

- Above the critical load, transition to severe wear occurs in unreinforced matrix alloy. But the reinforced MMCs have superior wear resistance.

- With increase in Graphene wear rate has decreased and is clear from the results that as the percentage of $\mathrm{S}$ - Glass increases in the composite the wear rate decreases, which is a good sign for production of low cost material.

- The best wear resistant combination is at $5 \%$ of SGlass and 1\% \&1.5\%of Graphene as consideration.
- In material Metal-metal and metal-particle wear resistance increased with increasing distance from the centre of the specimen. Worn surface examination of the material revealed formation of iron rich transfer layer during metal-metal wear test. Abrasive wear progressed by grooving action of the abrasion grains. Abrasion resistance of the composite was decreased with the size of particle. Composites exhibited abrupt increase in abrasion rate for higher speeds and loads.

\section{REFERENCES}

[1] A. K. Dhingra, "metal replacement by composite", JOM 1986, Vol 38 (03), p.17.

[2] R.L. Trumper Met. Mater, Vol. 3, 1987, p.662. MechmetAcilar, Ferhat Gul "Effect of applied load, sliding distance and oxidation on the dry sliding wear behaviour of $\mathrm{Al}-10 \mathrm{Si} / \mathrm{Cp}$ composites produced by vacuum infilatration techniques.

[3] Journal of Materials \& Design Vol.25, (2004) pp 209-217 \& Liu Yao-hui, Du Jun et.al. "High temperature friction and Wear behaviour of Al2O3and/or Carbon short fiber reinforced Al-1 Si alloy composites" Wear 56, 004, pp 75-285.

[4] A.Alahelisten, F.Bergman, M.Olsson, S.Hogmark, "on the wear of Aluminium and magnesium metal matrix composites", Wear Vol.165, 1993, pp1-226.

[5] J.Q.Jiang, R.S.Tan, A.B.Ma, "Dry sliding wear behaviour of $\mathrm{Al} 2 \mathrm{O} 3-\mathrm{Al}$ composite produced by centrifugal force infiltration", Material Science and Technology, Vol. 1, 1996, pp483-488.

[6] P.N.Bindhumadhan, H.K.Wah, O.Prabhakar, "Dual particle size (DPS) composites: effect on wear and mechanical properties of particulate matrix composites" Wear, Vol. 48, 2001, pp 112120.

[7] S. Tjong, S.Q. Wu, and H. Liao: "Wear behavior of an $\mathrm{Al}-12 \% \mathrm{Si}$ alloy reinforced with a low volume fraction of $\mathrm{Si}$ particles." Journal of composite 
science and technology, Vol-57, Issue-12, Dec 1997, pp1551-1558.

[8] S. Tjong, H.Z.Wang and S.Q.Wu "Wear Behavior of Aluminium based Metal Matrix Composites Reinforced with a Perform of Aluminium silicate Fiber" Metallurgical and Materials Transactions A, Vol 27A, (1996)2385-2389.

[9] M.Singh, D.P.Mondal et.al. "Development of light weight Aluminium alloy hard particle composite using natural minerals for wear resistance application. National conventions on emerging materials on wear applications. Paper no TS- 4/5, 2003, Bhopal.

\section{Cite this article as :}

Verma R., Dr. P. Vijaya Kumar, Meghashree K. A., Puneeth P., "Study of Wear Rate On Graphene and SGlass Reinforced Al-6061 Metal Matrix Composites ", International Journal of Scientific Research in Science and Technology (IJSRST), Online ISSN : 2395-602X, Print ISSN : 2395-6011, Volume 7 Issue 2, pp. 226-234, March-April 2020. Available at doi : https://doi.org/10.32628/IJSRST207238 Journal URL : http://ijsrst.com/IJSRST207238 